\title{
Kinetics of Precipitation of Nickel from Lead-Nickel Solid Solution
}

\author{
By R. Nozato*, T. Morigaki** and H. Tsubakino*
}

\begin{abstract}
Kinetics of $\mathrm{Ni}$ precipitation in $\mathrm{Pb}$-alloys containing $0.013-0.213$ at $\% \mathrm{Ni}$ was studied by measuring the resistivity of the alloys aged after quenching from $558 \mathrm{~K}$. During an isochronal aging $(45 \mathrm{~s})$, the resistivity decreases roughly in a single stage and then increases with rising temperature. The resistivity decreases in two distinct stages during isothermal aging of $\mathrm{Pb}-0.070$ at $\% \mathrm{Ni}$ alloy below $303 \mathrm{~K}$. The precipitation in the initial stage $\left(\mathbf{I}_{\mathbf{A}}\right)$ is a first-order reaction with an activation energy of $49.9 \pm 3.0 \mathrm{~kJ} / \mathrm{mol}$. The second stage $\left(\mathrm{II}_{\mathrm{A}}\right)$ is also a first-order reaction, but has a different value of activation energy, $100.3 \pm 4.0 \mathrm{~kJ} / \mathrm{mol}$. At $303 \mathrm{~K}$ or above, the resistivity decreases in a single stage $\left(I_{B}\right)$ during isothermal aging. The kinetics of stage $I_{B}$ is described by Johnson-Mehl's equation with a value of $2 / 3$ as the constant $n$. The activation energy for this stage is found to be $80.9 \pm$ $3.0 \mathrm{~kJ} / \mathrm{mol}$.

It is supposed that the precipitations in three stages $\mathbf{I}_{A}, \mathbf{I I}_{\mathbf{A}}$ and $\mathrm{I}_{\mathbf{B}}$ are controlled by diffusion of nickel interstitials, substitutionals and interstitial-vacancy pairs, respectively.

The solubility of nickel in solid lead determined in the present work was much lower than a previously accepted value.
\end{abstract}

(Received September 10, 1982)

Keywords: lead-nickel alloys, precipitation kinetics, electrical resistivity, interstitial atoms, interstitial-vacancy pairs, substitutional atoms, nickel solubility

\section{Introduction}

A transition metal Ni is one of "fast diffusers" in solid lead ${ }^{(1)(2)}$. It seems to be well established that the rate of precipitation of the fast diffusers from lead containing these impurities is connected with their volume diffusion ${ }^{(3)-(5)}$. Nickel diffuses in lead by a pure interstitial mechanism $^{(2)}$ at temperatures from 481 to $600 \mathrm{~K}$ : Interstitial Ni atoms are not trapped by vacancies at temperatures of diffusion ${ }^{(2)}$ or electromigration ${ }^{(6)}$ experiments. However, there is the possibility that the motion of nickel is suppressed by trapping of the interstitial $\mathrm{Ni}$ atoms at vacancies below solvus temperatures for $\mathrm{Ni}$. Thus the kinetics of $\mathrm{Ni}$ precipitation may be affected by the behavior of this trapping, and hence by the aging temperature.

The present paper describes a resistometric

* Department of Metallurgical Engineering, College of Engineering, University of Osaka Prefecture, Sakai 591, Japan.

** Graduate Student, University of Osaka Prefecture, Sakai 591, Japan. Present address: Mechanical \& Metal Industry Research \& Guidance Institute of Hyogo Prefecture, Miki 673-04, Japan. study on kinetics of precipitation of nickel from lead-nickel solid solution below solvus temperatures for nickel. During the present study, it was required to re-examine the solubility of nickel in solid lead. The $\mathrm{Ni}$ solvus obtained is also reported here.

\section{Experimental Procedure}

Techniques for preparation of alloys and measurements of resistivity were mainly similar to those described previously ${ }^{(5)}$. Lead-nickel alloys containing 0.013 to 0.213 at $\% \mathrm{Ni}$ were prepared in evacuated silica capsules $(2.7 \times$ $\left.10^{-3} \mathrm{~Pa}\right)$ at $973 \mathrm{~K}$ from $99.999 \%$ lead and $99.99 \%$ nickel. The alloy ingots were annealed at $558 \mathrm{~K}$ for $360 \mathrm{ks}(100 \mathrm{~h})$ in the capsules for homogeneization. The results of determination of $\mathrm{Ni}$ concentration in the alloy give the following values; $0.013,0.045,0.056,0.070,0.098$ and 0.213 at $\% \mathrm{Ni}$. Wire specimens, $1.7 \mathrm{~mm}$ in diameter and $75 \mathrm{~mm}$ in length, were prepared by cold rolling and drawing the alloy ingots. Before aging, the specimens were quenched into iced water after solution-annealing at $558 \mathrm{~K}$ for $3.6 \mathrm{ks}(1 \mathrm{~h})$. Two methods of aging treatment were employed; (a) isochronal aging at tem- 
peratures $T_{a}=195-563 \mathrm{~K}$ and (b) isothermal aging at $T_{a}=195-338 \mathrm{~K}$. The specimens were immersed in liquid nitrogen during the resistivity measurements. The resistivity of specimens was expressed as $\rho / \rho_{0}$ where $\rho_{0}$ is the resistivity in the as-quenched condition, and $\rho$ is that at the state aged for a time $t$.

\section{Experimental Results}

\section{Isochronal aging}

Figure 1(a) shows the result of isochronal aging (40 s) of a $\mathrm{Pb}-0.070$ at $\% \mathrm{Ni}$ alloy with increasing temperature with an interval of $10 \mathrm{~K}$ from $195 \mathrm{~K}$ to $563 \mathrm{~K}$. Figure 1(b) gives a nu-

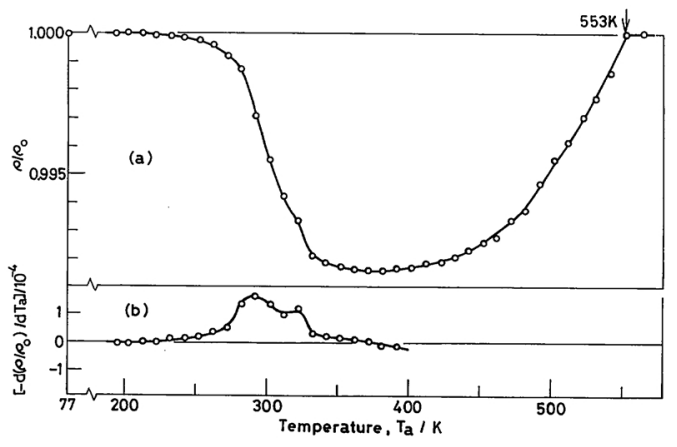

Fig. 1 Isochronal aging (40 s) curve for resistivity of $\mathrm{Pb}-0.070$ at $\% \mathrm{Ni}$ alloy quenched from $558 \mathrm{~K}$ : Curve (a). Curve (b) is numerical derivative of curve (a).

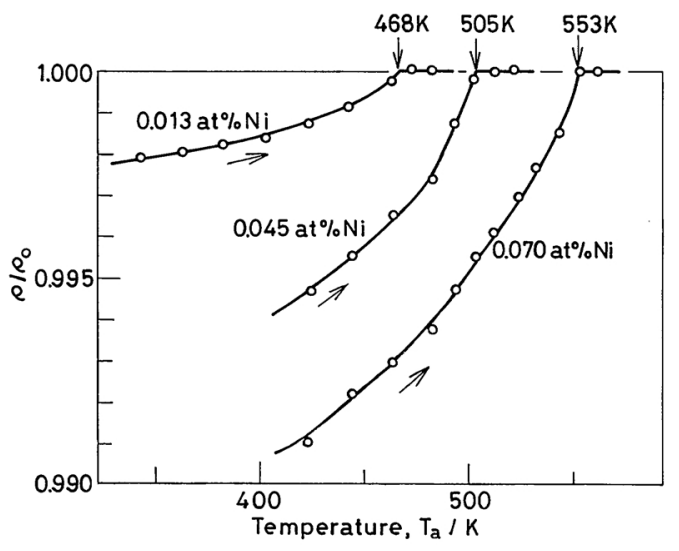

Fig. 2 Isochronal aging (40 s) curves for resistivity of $\mathrm{Pb}$ alloys containing $0.013,0.045$ and 0.070 at $\% \mathrm{Ni}$. All of the alloys were aged for $10.8 \mathrm{ks}$ at $328 \mathrm{~K}$ after quenching from $558 \mathrm{~K}$.

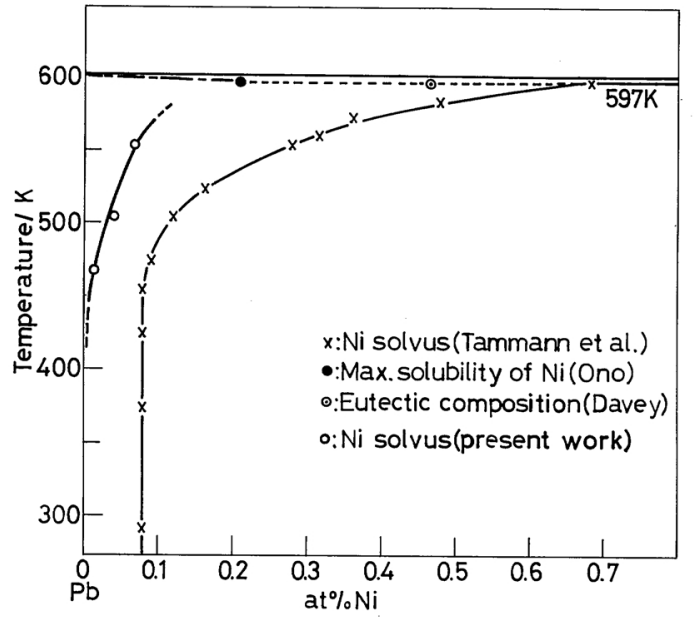

Fig. 3 Solubility of nickel in solid lead.

merical derivative of curve (a). With increasing temperature, the resistivity decreases first at $230-375 \mathrm{~K}$ roughly in a single stage, and then increases at $375-553 \mathrm{~K}$. The as-quenched resistivity $\rho_{0}$ is restored at $553 \mathrm{~K}$, which is regarded as the solvus temperature for $\mathrm{Ni}$ in this alloy. Figure 2 shows parts of resistivity-increase in an isochronal aging curve similar to Fig. 1(a), for several alloys of various concentrations of $\mathrm{Ni}$. These restoring temperatures obtained here were plotted against the Ni concentration of the alloys in Fig. 3. The resulting $\mathrm{Ni}$ solvus is shown by a curve accompanying open circles. The temperature dependence of the present solubility of $\mathrm{Ni}$ in solid lead was found to be expressed at temperatures below $570 \mathrm{~K}$ by

$$
c_{e}=(770 \pm 200) \exp [-(41900 \pm 1000) / R T],
$$

where $c_{e}$ is in at $\% \mathrm{Ni}$, and $R$ the gas constant in $\mathrm{J} /(\mathrm{mol} \cdot \mathrm{K})$.

\section{Isothermal aging}

In Fig. 4, typical aging-curves at various temperatures $T_{a}$ are shown for $\mathrm{Pb}-0.070$ at $\% \mathrm{Ni}$ alloy. The resistivity decays in two distinct stages $\left(\mathrm{I}_{\mathrm{A}}\right.$ and $\left.\mathrm{II}_{\mathrm{A}}\right)$ below $303 \mathrm{~K}$ (in range $\mathrm{A}$ ). At $303 \mathrm{~K}$ or above (in range $\mathrm{B}$ ), the resistivity decreases in a single stage $I_{B}$. In this figure, $t_{f}^{1}$ is the time to finish the first stage $\mathrm{I}_{\mathrm{A}}$ or $\mathrm{I}_{\mathrm{B}}$, and $t_{s}^{\mathrm{II}}$ and $t_{f}^{\mathrm{II}}$ are respectively times for initiation and termination of the second stage $\mathrm{II}_{\mathrm{A}}$. 


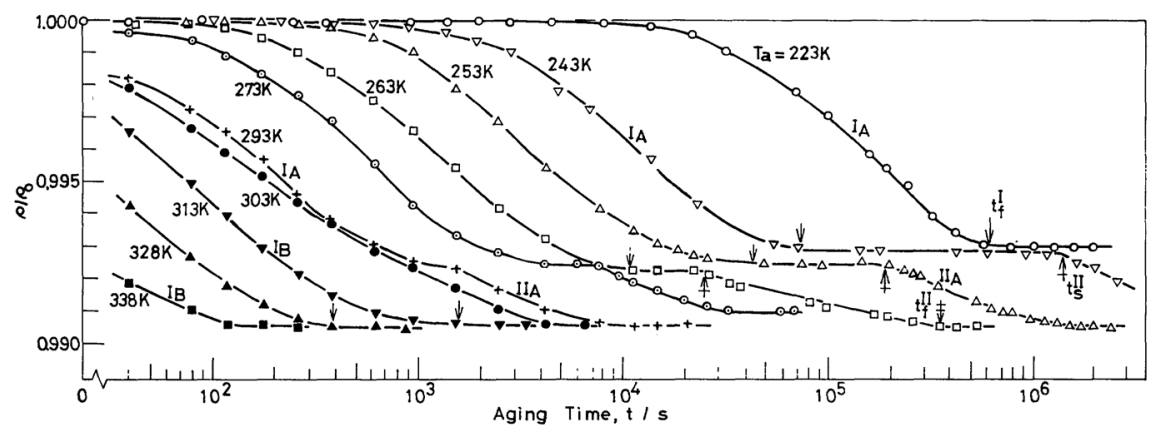

Fig. 4 Isothermal aging curves at various temperatures $\left(T_{a}\right)$ for resistivity of $\mathrm{Pb}-0.070$ at $\% \mathrm{Ni}$ alloy quenched from $558 \mathrm{~K}$. Arrow $\downarrow$ shows example of time $t_{f}^{1}$ to finish first stage $\mathrm{I}_{\mathrm{A}}$ or $\mathrm{I}_{\mathrm{B}}$; $\downarrow$, time $t_{s}^{\mathrm{II}}$ to initiate second stage $\mathrm{II}_{\mathrm{A}}$; and $\neq$, time $t_{f}^{\mathrm{II}}$ to finish stage $\mathrm{II}_{\mathrm{A}}$.

\section{Kinetic law}

The fractional resistivity change after time $t$, $f^{\mathrm{I}}$, was determined from Fig. 4 for stage $\mathrm{I}_{\mathrm{A}}$ or $\mathrm{I}_{\mathrm{B}}: f^{\mathrm{I}}=\left(\rho_{0}-\rho\right) /\left(\rho_{0}-\rho_{f}^{\mathrm{I}}\right)$, where $\rho_{f}^{\mathrm{I}}$ is the resistivity to finish stage $I_{A}$ or $I_{B}$, that is, the resistivity at $t_{f}^{\mathbf{I}}$. In Fig. 5, the logarithm of $\left(1-f^{\mathrm{I}}\right)$ was plotted against $t$ for stage $\mathrm{I}_{\mathrm{A}}$. This figure exhibits that a simple exponential-decay occurs in stage $I_{A}$. For stage $I_{B}$, however, the logarithm of $\left(1-f^{\mathrm{I}}\right)$ vs $t$ relation is not linear: No simple exponential-decay occurs in stage $I_{B}$ (the figure is not shown in this paper). Thus, $\log \log [1 /$ $\left(1-f^{I}\right)$ ] was plotted against the logarithm of $t$ for stage $I_{B}$ in Fig. 6. This plot indicates that the $\mathbf{I}_{B}$-decay can be expressed by Johnson-Mehl's equation,

$$
f^{\mathrm{I}}=1-\exp \left(-b t^{n}\right),
$$

with a $n$-value of $2 / 3$ on the average. This value of $n$ suggests that the $\mathrm{Ni}$ atoms in $\mathrm{Pb}$ are attracted to dislocations in a manner similar to

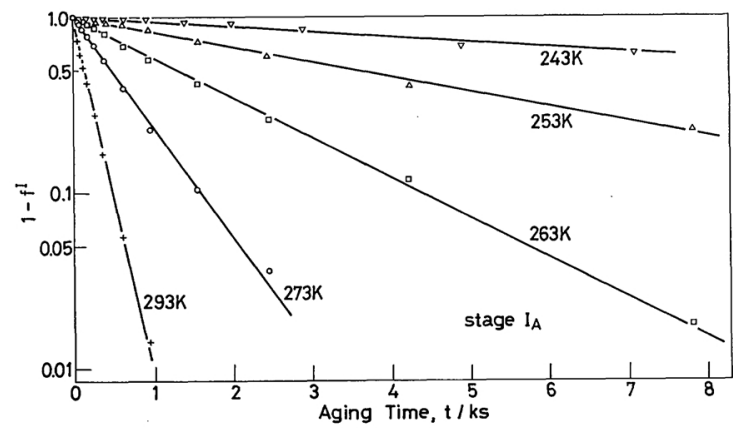

Fig. 5 Logarithms of remaining fractional decay $\left[1-f^{\mathbf{I}}=\left(\rho-\rho_{f}^{\mathbf{I}}\right) /\left(\rho_{0}-\rho_{f}^{\mathbf{I}}\right)\right]$ as a function of aging time $(t)$ in stage $\mathrm{I}_{\mathrm{A}}$, for $\mathrm{Pb}-0.070$ at $\% \mathrm{Ni}$ alloy.

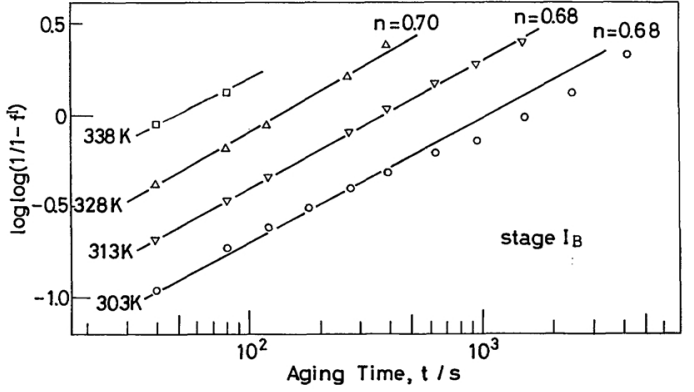

Fig. 6 Plots of $\log \log \left[1 /\left(1-f^{\mathrm{l}}\right)\right]$ against $\log t$ for stage $\mathrm{I}_{\mathrm{B}}$ of $\mathrm{Pb}-0.070$ at $\% \mathrm{Ni}$ alloy.

the case of interstitial carbon atoms in $\mathrm{Fe}^{(7)}$. The fractional resistivity change after $t, f^{\mathrm{II}}$, was determined for stage $\mathrm{I}_{\mathrm{A}}$ from Fig. 4: $f^{\mathrm{II}}=$ $\left(\rho_{f}^{\mathrm{I}}-\rho\right) /\left(\rho_{f}^{\mathrm{I}}-\rho_{f}^{\mathrm{II}}\right)$, where $\rho_{f}^{\mathrm{II}}$ is the resistivity to finish stage $\mathrm{II}_{\mathrm{A}}$, that is, the resistivity at $t^{\mathrm{II}}$. Figure 7 shows the logarithm of $\left(1-f_{f}^{\mathrm{II}}\right)$ plotted against $\left(t-t_{f}^{\mathrm{II}}\right)$. This figure indicates that the $\mathrm{II}_{\mathrm{A}}$-decay obeys a simple exponential kinetics.

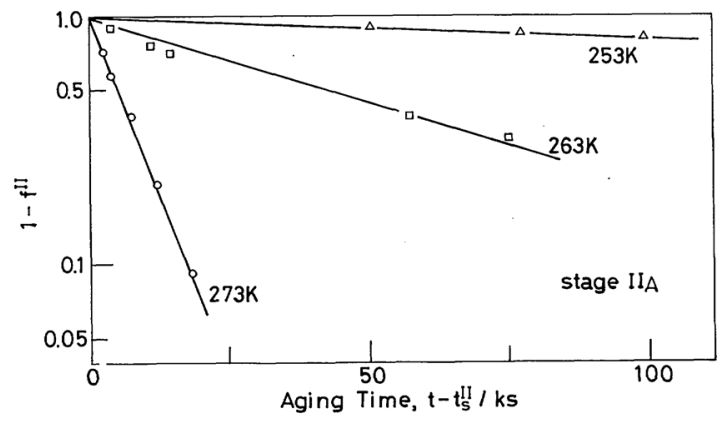

Fig. 7 Logarithms of remaining fractional decay $\left[1-f^{\mathrm{II}}=\left(\rho-\rho_{f}^{\mathrm{II}}\right) /\left(\rho_{f}^{\mathrm{I}}-\rho_{f}^{\mathrm{II}}\right)\right]$ as a function of aging time $\left(t-t_{s}^{\mathrm{II}}\right)$ in stage $\mathrm{II}_{\mathrm{A}}$, for $\mathrm{Pb}-0.070$ at $\% \mathrm{Ni}$ alloy. 


\section{Activation energy}

Figure 8 shows Arrhenius plots of $t_{0.5}^{\mathrm{I}}$ and $t_{f}^{\mathrm{I}}$ at $T_{a}$ not higher than $273 \mathrm{~K}$, where $t_{0.5}^{\mathrm{I}}$ is the time to complete one-half of stage $I_{A}$ and can be determined from Fig. 4 . The $t_{0.5}^{\mathrm{I}}$ and $t_{f}^{\mathrm{I}}$ reflect the rate constants in the central and later parts of the first-order reaction occurring in stage $I_{A}$. These two plots yield almost identical values $(50.2$ and $48.5 \mathrm{~kJ} / \mathrm{mol})$ of activation energy $(Q)$, and the average value $49.4 \pm 3.0 \mathrm{~kJ} / \mathrm{mol}$ is taken as $Q$ for the stage $\mathrm{I}_{\mathrm{A}}$. Figure 8 shows also the Arrhenius plots of $t_{s}^{\mathrm{II}}$ and $t_{f}^{\mathrm{II}}$ which reflect the

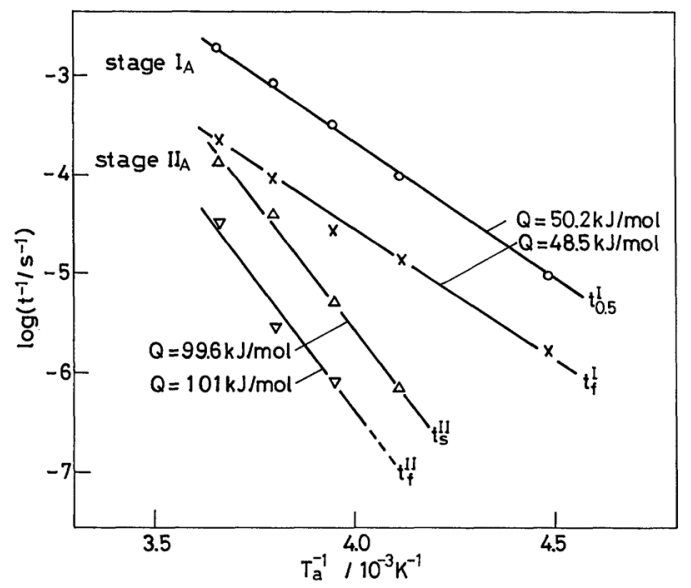

Fig. 8 Arrhenius plots of $t_{0.5}^{1}, t_{f}^{\mathrm{I}}, t_{s}^{\mathrm{II}}$ and $t_{f}^{\mathrm{I}}$ in stages $\mathrm{I}_{\mathrm{A}}$ and $\mathrm{II}_{\mathrm{A}}$, for $\mathrm{Pb}-0.070$ at $\% \mathrm{Ni}$ alloy.

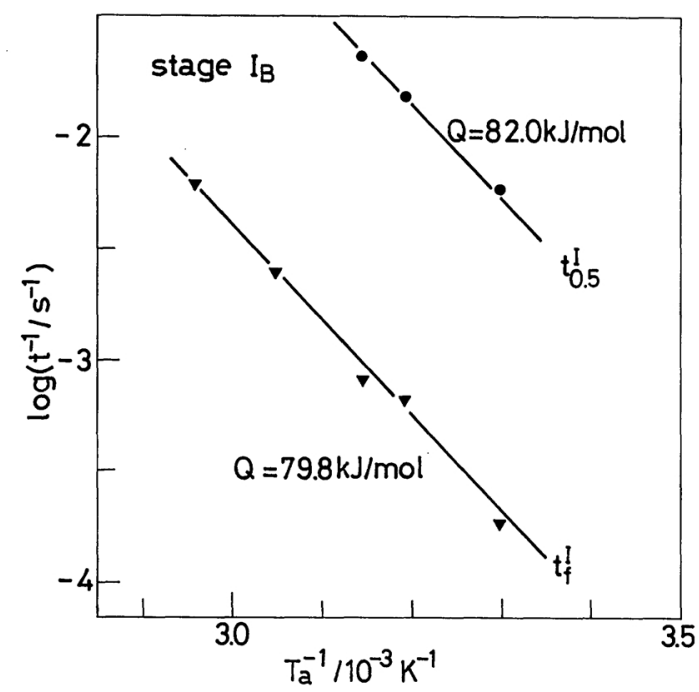

Fig. 9 Arrhenius plots of $t_{0.5}^{\mathrm{I}}$ and $t_{f}^{\mathrm{I}}$ in stage $\mathrm{I}_{\mathrm{B}}$, for $\mathrm{Pb}-0.070$ at $\% \mathrm{Ni}$ alloy. rate constants in the initial and later parts of the first-order reaction occurring in stage $\mathrm{II}_{\mathrm{A}}$. These two plots yield almost identical values ( 99.6 and $101 \mathrm{~kJ} / \mathrm{mol}$ ) of $Q$, and the average value $100.3 \pm$ $4.0 \mathrm{~kJ} / \mathrm{mol}$ is taken as $Q$ for the stage $\mathrm{II}_{\mathrm{A}}$. Arrhenius plots of $t_{0.5}^{\mathrm{I}}$ and $t_{f}^{\mathrm{1}}$ at $T_{a}=303-$ $338 \mathrm{~K}$ are shown in Fig. 9, where $t_{0.5}^{\mathrm{I}}$ is the time to complete one-half of stage $\mathrm{I}_{\mathrm{B}}$. The value of $t_{0.5}^{\mathrm{I}}$ cannot be determined at $T_{a}$ above $323 \mathrm{~K}$, because of a rapid progress of this stage. The plots give an average value of $Q, 80.9 \pm 3.0 \mathrm{~kJ} /$ mol, for the first-order reaction in stage $I_{B}$.

\section{Discussion}

\section{Solubility of nickel in solid lead}

It has been repeatedly proposed that the solubility of nickel in solid lead should be reinvestigated $^{(8)(9)}$, although the $\mathrm{Ni}$ solvus was determined by the magnetic method and 0.68 at $\%(0.195$ mass $\%) \mathrm{Ni}$ was accepted as the maximum solubility of nickel in solid lead at $600 \mathrm{~K}^{(10)}$. These proposals are based on the facts that 0.38 at $\% \mathrm{Ni}$ is found as a eutectic composition at $597 \mathrm{~K}$ near $\mathrm{Pb}$ in the $\mathrm{Pb}-\mathrm{Ni}$ system $^{(11)}$, and that a considerable grain refinement occurs in $\mathrm{Pb}-\mathrm{Ni}$ alloys containing about 0.1 at $\% \mathrm{Ni}^{(9)}$. A value of the eutectic composition, 0.46 at $\% \mathrm{Ni}$, reported more recently ${ }^{(12)}$ is also lower than the maximum solubility accepted previously. The present values

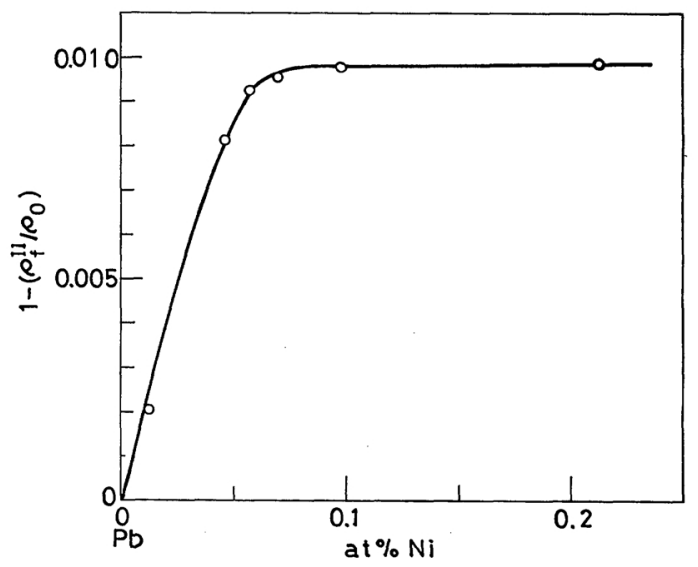

Fig. 10 Decrement of $\rho / \rho_{0}$ due to completion of precipitation at $293 \mathrm{~K}$ after quenching from $558 \mathrm{~K}$, $1-\left(\rho_{f}^{\mathrm{U}} / \rho_{0}\right)$, as a function of $\mathrm{Ni}$ concentration of alloys. 
for the solubility shown in Fig. 3 are an order of magnitude lower than the previously accepted value, but is not inconsistent with both the eutectic compositions described above and with a maximum solubility of $\mathrm{Ni}$ in solid lead, 0.21 at $\% \mathrm{Ni}$, reported by $\mathrm{Ono}^{(13)}$. In Fig. 10 the decrement of $\rho / \rho_{0}$ due to the completion of precipitation of $\mathrm{Ni}$ at $293 \mathrm{~K}$ after quenching from $558 \mathrm{~K}, 1-\left(\rho_{f}^{\mathrm{II}} / \rho_{0}\right)$, was plotted against the $\mathrm{Ni}$ concentration of the alloys. The resulting curve prefers a value of $0.087 \mathrm{at} \% \mathrm{Ni}$ given from eq. (1) rather than 0.317 at $\% \mathrm{Ni}$ reported previously ${ }^{(10)}$ as the solubility of nickel in solid lead at $558 \mathrm{~K}$.

\section{Precipitation kinetics}

Three different values were observed for the activation energy in different stages of precipitation of nickel from the $\mathrm{Pb}-\mathrm{Ni}$ solid solution. The value $49.4 \mathrm{~kJ} / \mathrm{mol}$ for stage $I_{A}$ is fairly in agreement with that $44.4 \mathrm{~kJ} / \mathrm{mol}^{(2)}$ for diffusion of interstitial $\mathrm{Ni}$ atom, and the value $100.3 \mathrm{~kJ} /$ mol for stage $\mathrm{II}_{\mathrm{A}}$ agrees well with $101.3 \mathrm{~kJ} /$ $\mathrm{mol}^{(14)}$ for self-diffusion of lead. Since both stages $\mathrm{I}_{\mathrm{A}}$ and $\mathrm{II}_{\mathrm{A}}$ are of simple first-order reaction, it is supposed that the $\mathrm{Ni}$ transport during precipitation in these stages is controlled by the migration of interstitials and substitutionals, respectively, to a fixed number of precipitate nuclei. The value of activation-energy, $80.9 \mathrm{~kJ} /$ mol, for stage $I_{B}$ is in fair agreement with that $87.0 \mathrm{~kJ} / \mathrm{mol}$ found by Rossolimo et al. ${ }^{\left({ }^{3)}\right.}$ for precipitation of $\mathrm{AuPb}_{3}$ from $\mathrm{Pb}-\mathrm{Au}$ solid solution. These authors considered from this activation energy that the precipitation of $\mathrm{AuPb}_{3}$ is controlled by diffusion of interstitialvacancy $(i v)$ pairs or diinterstitial-vacancy $\left(i_{2} v\right)$ clusters (split interstitials), where $i$ is the interstitial $\mathrm{Au}$ atom and $v$ the vacancy. Thus the present value of activation energy is also attributed to activation energy for diffusion of interstitial $\mathrm{Ni}$ atom-vacancy(iv) pairs or $i_{2} v$ cluster. Since the kinetic law for this stage can be described by Johnson-Mehl's equation with $n=2 / 3$, the $i v$ pairs or $i_{2} v$ clusters are considered to be attracted to dislocations during the precipitation.

Diffusivity $^{(2)}$ and electromigration ${ }^{(6)}$ data suggest that most of the dissolved $\mathrm{Ni}$ is in an interstitial state and moves in a simple inter- stitial mechanism above solvus temperatures for Ni. The present precipitation data, however, reveal that attractive interactions are present between interstitial $\mathrm{Ni}$ atoms and vacancies: Interstitials may be trapped by vacancies with a reaction, (a) $i+v \rightarrow s$, or (b) $i+v \rightarrow i v$, depending upon the aging temperature below the solvus temperatures for $\mathrm{Ni}$, where $s$ is a substitutional $\mathrm{Ni}$ atom. For simplicity we ignore the formation of higher order defects or clusters (e.g., $i_{2} v$ cluster) in the present discussion. We suppose that in the condition as-quenched from $558 \mathrm{~K}$ the nickel atoms are primarily in the interstitial state. The concentration of the interstitial atom may be much higher than that of vacancy at the biginning of aging below $303 \mathrm{~K}$. Then the first stage of the precipitation would occur with transport of the excess free interstitials to the precipitate nuclei (stage $I_{A}$ ). At the end of stage $I_{A}$, only the interstitials trapped by vacancies remain untransported to the nuclei. These interstitials may become substitutionals due to reaction (a). The substitutional atoms may precipitate in $\mathrm{II}_{\mathrm{A}}$, the later stage of aging. Assuming that formation entropy is larger for iv pair than for $s$, we suppose that the interstitials are trapped by vacancies to produce $i v$ pairs with reaction (b) rather than with (a), at a temperature of $303 \mathrm{~K}$ or above (in rangeB). These iv pairs may precipitate in stage $\mathrm{I}_{\mathrm{B}}$. Since only single stage $I_{B}$ occurs in range $B$, most of the interstitials must be trapped by vacancies at the beginning of the aging. The equilibrium concentration of vacancy in pure lead ${ }^{(15)}$ at $333 \mathrm{~K}$-namely, a temperature above $303 \mathrm{~K}$-is about $10^{-7}$, which is too low in concentration to trap most of the interstitials quenched-in from $558 \mathrm{~K}$ when the vacancy can trap only one interstitial $\mathrm{Ni}$ atom to produce $i v$ pair. Thus it is again supposed that an attractive interaction is present between the interstitials and the vacancies, and the vacancy concentration may be higher in the $\mathrm{Pb}-\mathrm{Ni}$ alloys than in the pure lead.

On the basis of this model for precipitation, the rate constants $\left(k_{\mathrm{IA}}, k_{\mathrm{IIA}}\right.$ and $\left.k_{\mathrm{IB}}\right)$ for the precipitations in stages $\mathrm{I}_{A}, \mathrm{II}_{\mathrm{A}}$ and $\mathrm{I}_{B}$ may be given by the expressions

$$
k_{\mathrm{IA}}=A_{1} \exp \left(-E_{i} / k T\right),
$$




$$
k_{\mathrm{IIA}}=A_{2} \exp \left[-\left(E_{i}+B_{s}\right) / k T\right]
$$

and

$$
k_{\mathrm{IB}}=A_{3} \exp \left[-\left(E_{i}+B_{i v}\right) / k T\right],
$$

where $A_{1}, A_{2}$ and $A_{3}$ are the frequency factors, $E_{i}$ the migration energy of the free interstitial nickel atom, and $B_{s}$ and $B_{i v}$ the binding energies between interstitial nickel atom and vacancy participating in the formation of substitutional nickel atom and interstitial-vacancy pair, respectively. Thus, three experimental values of activation energy for each stage are assigned as follows: $E_{i}=49.4 \mathrm{~kJ} / \mathrm{mol}, \quad E_{i}+B_{s}=100.3 \mathrm{~kJ} /$ mol, and $E_{i}+B_{i v}=80.9 \mathrm{~kJ} / \mathrm{mol}$. Therefore, we have $B_{s}=50.9 \mathrm{~kJ} / \mathrm{mol}$ and $B_{i v}=31.5 \mathrm{~kJ} / \mathrm{mol}$.

\section{Conclusion}

(1) During an isochronal aging (40 s), the resistivity decreases first roughly in a single stage and then increases with rising temperature up to a restoring temperature, at which the asquenched resistivity is recovered. The restoring temperature, which is regarded as the solvus temperature for nickel, is not in agreement with that accepted previously.

(2) The resistivity decreases in two distinct stages during isothermal aging of $\mathrm{Pb}-0.070$ at \% $\mathrm{Ni}$ alloy below $303 \mathrm{~K}$ (in range $\mathrm{A}$ ). The precipitation in the initial stage $\left(\mathrm{I}_{\mathrm{A}}\right)$ is a first-order reaction with an activation energy of $49.4 \pm$ $3.0 \mathrm{~kJ} / \mathrm{mol}$. The second stage $\left(\mathrm{II}_{\mathrm{A}}\right)$ is also a firstorder reaction, but has a different value of activation energy, $100.3 \pm 4.0 \mathrm{~kJ} / \mathrm{mol}$.

(3) At $303 \mathrm{~K}$ or above (in range $\mathrm{B}$ ), the resistivity decreases in a single stage $\left(I_{B}\right)$ during isothermal aging of the alloy. The precipitation kinetics of this stage is described by JohnsonMehl's equation with a value of $2 / 3$ as the constant $n$. The activation energy is found to be $80.9 \pm 3.0 \mathrm{~kJ} / \mathrm{mol}$ for this stage.

(4) It is supposed that the precipitations in stages $\mathrm{I}_{\mathrm{A}}$ and $\mathrm{II}_{\mathrm{A}}$ are controlled by diffusion of free interstitial and substitutional $\mathrm{Ni}$ atoms, respectively, to precipitate nuclei, while that in stage $I_{B}$ is due to migration of interstitial $\mathrm{Ni}$ atom-vacancy pairs to dislocations.
(5) From the present model for precipitation, the binding energy between interstitial nickel atom and vacancy was estimated to be $31.5 \mathrm{~kJ} / \mathrm{mol}$ with production of interstitialvacancy pair and $50.9 \mathrm{~kJ} / \mathrm{mol}$ with that of substitutional nickel atom.

(6) The solubility of nickel in solid lead was redetermined in the present work. The resulting values were an order of magnitude lower than the previously accepted values.

\section{Acknowledgments}

The authors are grateful to Dr. H. Nakajima, Tohoku University, for valuable advice on nickel solvus in the $\mathrm{Pb}-\mathrm{Ni}$ system. They also wish to thank Mr. M. Terada, Mr. M. Iwamoto and Mr. K. Nigo, undergraduate students, for the experimental aids.

\section{REFERENCES}

(1) W. K. Warburton and D. Turnbull: Diffusion in Solids, ed. by A. S. Nowick and J. J. Burton, Academic Press (New York), (1975), p. 171.

(2) C. T. Candland and H. B. Vanfleet: Phys. Rev., B7 (1973), 575.

(3) A. N. Rossolimo and D. Turnbull: Acta Met., 21 (1973), 21.

(4) B. M. Cohen and D. Turnbull: Acta Met., 26 (1978), 113.

(5) R. Nozato and T. Yamaji: Trans. Japan Inst. Metals, 21 (1980), 131.

(6) D. A. Golopentia and H. B. Huntington: J. Phys. Chem. Solids, 39 (1978), 975.

(7) M. E. Fine: Introduction to Phase Transformations in Condensed Systems, Macmillan (New York), (1964), p. 62.

(8) M. Hansen and K. Anderko: Constitution of Binary Alloys, McGraw-Hill (New York), (1958), p. 1028.

(9) W. Hofmann: Lead and Lead Alloys, Springer (Berlin), (1970), p. 69.

(10) G. Tammann and W. Oelsen: Z. anorg. allg. Chem., 186 (1930), 257.

(11) E. Pelzel: Metall, 9 (1955), 692.

(12) T. R. A. Davey: AIME Met. Soc. Conference, Vol. 7, Physical Chemistry of Process Metallurgy, Interscience (New York), (1961), p. 581.

(13) K. Ono: Lead and Lead Alloys, Sankaido (Tokyo), (1942), p. 66 (in Japanese).

(14) N. H. Nachtrieb and G. S. Handler: J. Chem. Phys., 23 (1955), 1569.

(15) R. Feder and A. S. Nowick: Phil. Mag., 15 (1967), 805 . 